\title{
A Longitudinal Examination of the Association Between Psychological Capital, Perception of Organizational Virtues and Work Happiness in School Staff
}

\author{
Paige Williams*, Margaret L Kern and Lea Waters
}

${ }^{*}$ Correspondence:

paige.williams@unimelb.

edu.au

Centre for Positive

Psychology Melbourne Graduate School, University of Melbourne, 100 Leicester Street, Parkville, VIC 3010

Australia

\begin{abstract}
Background: Developing employee wellbeing has recently been recognized as an important way to improve organizational performance. Sloan's (1987) dual-intervention approach suggests that employee wellbeing can be developed bottom-up, by improving employee psychological wellbeing, or top-down by changing the organization. This longitudinal study explores the association between psychological capital (bottom-up factors), organizational virtues (top-down factors), and work happiness.
\end{abstract}

Method: A three-wave repeated measures correlation study was used to analyze the pattern of relationships between employee psychological capital (PsyCap), perception of organizational virtues (OV) and work happiness in staff at an independent K-12 school in Victoria, Australia over a 15-month timespan (baseline $\mathrm{N}=247$ ).

Results: Within and across time, both employee psychological capital and perception of organizational virtues independently related to greater work happiness. PsyCap and OV strongly correlated with work happiness, with a simplex structure i.e., variables closer in time were more strongly correlated, with correlation strength declining over time. Further, there was some evidence of a small of a synergistic effect.

Results: The results suggest that while leaders might target psychological capital in employees or target the organization's culture to develop employee wellbeing, further benefit may arise by using both top-down and bottom-up strategies. These findings can be used to help schools and other organizations build employee work happiness.

\section{Background}

One major source of strategic capital in today's information and knowledge-driven society is people (Lorange 2005). Certainly, the nature of business has shifted from a concentration on financial capital to a concentration on human capital (Bartlett and Ghoshal 2002), suggesting that an organization's people are critical to its innovation, performance and competitiveness. As such, employee wellbeing has gained recognition as an important outcome that organizations need to foster if they are to make best use of the capacity of their human capital and perform well.

Increasing evidence from the field of positive psychology suggests that optimal levels of wellbeing influence positive outcomes for employees and organizations. Wellbeing in

(c) 2015 Williams et al. This article is distributed under the terms of the Creative Commons Attribution 4.0 International License (http://creativecommons.org/licenses/by/4.0/), which permits unrestricted use, distribution, and reproduction in any medium, provided you give appropriate credit to the original author(s) and the source, provide a link to the Creative Commons license, and indicate if changes were made. 
employees has been related to their levels of engagement (Harter et al. 2003), organizational citizenship behaviors (LePine et al. 2002) and overall career success (Boehm and Lyubomirsky 2008). For organizations, employee wellbeing is linked with customer satisfaction, (Giardini and Frese 2008) productivity, presenteeism, and effort at work (Keyes 2005); lower voluntary turnover (Wright and Bonett 2007) and fewer absenteeism/sick days (Keyes 2005). Organizations who develop employee wellbeing receive a positive return on investment through reduced absenteeism and compensation claims (Price Waterhouse Coopers 2014). As such, it is in the interest of organizations to intentionally develop employee wellbeing.

Happiness and wellbeing at work has been defined in a number of ways. Definitions include: the presence of positive experiences and absence of negative experiences (Cotton and Hart 2003); workplace affect and job satisfaction (Page and Vella-Brodrick 2009) and more broadly as a positive state of mind arising from one's experiences at work (Page 2005). Fisher (2010) proposes that happiness at work should be treated as a multidimensional concept, and argues that measures of work happiness such as job satisfaction (Locke 1976), positive affect (Fisher 1997) and thriving and vigor (Spreitzer and Sonenshein 2004) are too narrow. She proposes a higher-order approach to conceptualizing 'work happiness' and suggests it is the combination of three aspects: (a) engagement with the work itself; (b) satisfaction with the job and, (c) feelings of affective commitment to the organization as a whole. This multi-dimensional model of work happiness parallels recent developments in wellbeing theory to multi-dimensional frameworks (e.g. Huppert and So 2013; Seligman 2011).

Each of the individual elements of Fisher's (2010) model of work happiness has a conceptual and theoretical evidence base. Work engagement is defined as comprising cognitive, affective and behavioral elements in relation to an individual's performance of their job role (Schaufeli and Bakkar 2003). Engaged employees have influence over events in their lives through their energy and self-efficacy (Bakker and Demerouti 2008), they create their own positive feedback through their positive attitude and activity level, and consider work to be fun (Gorgievski et al. 2010). Job satisfaction is defined as "an evaluative state that expresses contentment with, and positive feelings about one's job" (Judge and Kammeyer-Mueller 2012, p. 347). This suggests that it includes both cognition (contentment) and affect (positive feelings), and that overall job satisfaction is the result of a process of evaluation of individual job facets or characteristics. Evidence suggests that high levels of job satisfaction relate to job performance (Judge et al. 2001), and psychological and physical health (Faragher et al. 2005). Affective organizational commitment is an organization member's emotional attachment to, identification with and involvement in the organization (Meyer and Allen 1984; Allen and Meyer 1990). Employees with high levels of affective commitment have been found to have higher job performance and organizational citizenship behaviors, and lower absenteeism and intentions to quit (Meyer et al. 2002).

By presenting work happiness as a higher-order construct that comprises the unique and shared variance of these three factors, Fisher suggests that workplace leaders can move beyond boosting each of the variables individually and capitalize on the synergistic effects that occur when the three variables interact. This also allows for more sustainable ways to promote work happiness because if an employee is low on one aspect of work 
happiness (e.g., engagement) but has high levels of the other elements (e.g., satisfaction and commitment) they can still achieve happiness at work.

To date, Fisher's higher-order conceptualization of work happiness has not been tested empirically; thus one purpose of this study is to provide an initial test of the model. This is needed because Fisher's model has practical implications for how leaders increase the work happiness of their staff. The traditional approach to increasing happiness has been for researchers and leaders to create change in a raft of the antecedents that have been previously shown to influence engagement, satisfaction and commitment respectively. For example, evidence suggests that numerous factors relate to greater work engagement, such as relationships with colleagues, performance feedback, skill variety, autonomy, learning opportunities, resilience, personal attachment, and supervisor and co-worker support (e.g., Albrecht 2010; Armutlulu and Noyan 2011; Bakker and Demerouti 2008; Hackman and Oldham 1976; Hobfoll et al. 2003; Judge et al. 2004; Morrow 2011). Such research has provided leaders with a large 'shopping list', and it is not surprising that leaders may feel confused by what to do or feel that their approaches are overly complex. For example, how do leaders decide whether to change job characteristics or improve employee attachment or be more considerate themselves as leaders? Instead, by using a higher-order approach to work happiness, leaders can adopt a more parsimonious approach to creating the conditions for employee work happiness.

In this study, we propose that Sloan's (1987) dual-intervention approach can be used to foster work happiness. Sloan (1987) suggests that organizational-level factors such as culture may influence participation in and outcomes of workplace health promotion programs and also proposes that individual-level interventions are required. That is, both top-down, organizational factors and bottom-up individual-level factors matter. The current study examines the naturally occurring relationships between the top-down variable of employee perception of organizational virtue and the bottom-up variable of employee psychological capital on work happiness over time. See Fig. 1.

Psychological capital (PsyCap) is a higher-order factor that comprises an employee's levels of self-efficacy, optimism, hope and resilience (Luthans et al. 2006). Heralding from the field of positive organizational behavior, PsyCap is defined as:

"an individual's positive psychological state of development characterized by: (1) having confidence (self-efficacy) to take on and put in the necessary effort to succeed at challenging tasks; (2) making a positive attribution (optimism) about succeeding now and in the future; (3) persevering toward goals and, when necessary, redirecting paths to goals (hope) in order to succeed; and (4) when beset by problems and adversity, sustaining and bouncing back and even beyond (resilience) to attain success" (Luthans et al. 2006, p. 3).

PsyCap has been empirically linked to a number of desirable employee outcomes including: improved performance in the workplace (Luthans et al. 2005, 2007), lower employee absenteeism (Avey et al. 2006), higher job satisfaction, (Luthans et al. 2007), organizational commitment (Luthans and Jensen 2005) and psychological wellbeing (Avey et al. 2010). However, the relationship between PsyCap and Fisher's (2010) work happiness has not been tested. 


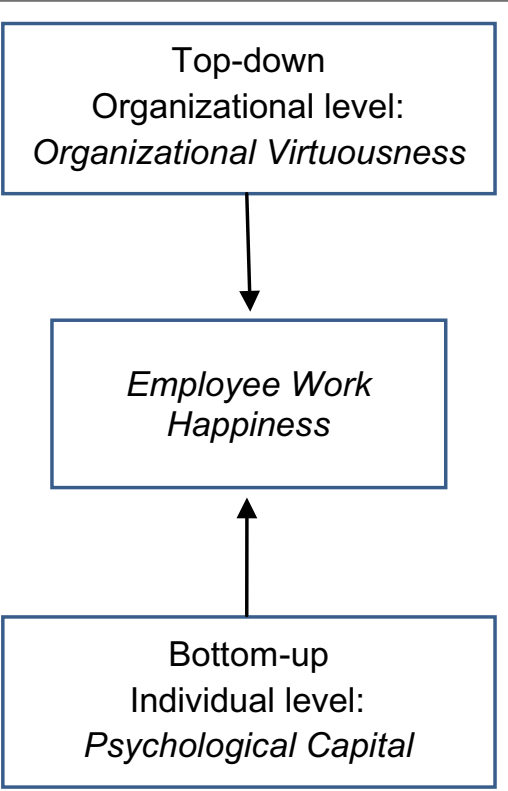

Fig. 1 A dual-approach model to developing employee work happiness.

In addition to this individual-level factor, Sloan (1987) advocates that leaders must look at organizational-level factors that may influence workplace health. The current study thus examines the influence of work environment; specifically the presence of virtues, on employee happiness at work. Virtues are positive traits representing the best of the human condition such as hope, optimism, kindness and curiosity, which have been shown to be valued across time and culture (Peterson and Seligman 2004). Park and Peterson (2003) suggest that counterparts are present at the organizational-level that embody the moral characteristics of the organization and are an enduring part of its culture.

Within the field of positive organizational scholarship, Cameron et al. (2003) proposes that virtuousness in an organization is operationalized via the behaviors' of individuals and through workplace processes and practices. Research by Cameron et al. (2004) suggested that organizational virtuousness (OV) is a higher-order construct that comprises five virtues: (a) organizational forgiveness, through which mistakes are quickly forgiven and used as opportunities for learning; (b) organizational trust, in the courtesy, consideration and respect enacted in the organization and the mutual trust between peers and leaders; (c) organizational integrity, demonstrated by the honesty, trustworthiness and honor that pervade the organization; (d) organizational optimism, in the belief of organizational members that they will succeed in doing well even in the face of challenges; and (e) organizational compassion, through the common acts of compassion and concern that show that people care about each other. Thus, a workplace that embodies OV demonstrates values such as forgiveness, trust, integrity, optimism and compassion both in the behavior of individual employees and through the processes and practices in the workplace. Research across multiple industries has found that the presence of organizational virtuousness correlates with greater improvement in indicators such as profitability, quality, productivity, customer satisfaction and employee retention (Cameron et al. 
2004). However, the relationship between organizational virtuousness (OV) and Fisher's (2010) higher order factor of work happiness has not been tested.

The current research examines relationships between employee PsyCap, perception of $\mathrm{OV}$ and work happiness in school staff. There has been growing interest in the study of wellbeing in schools in recent years as interventions from positive psychology have been applied and tested in school environments in what has become known as Positive Education (e.g. Seligman et al. 2009; Norrish et al. 2013; Waters 2011; Kern et al. 2014a). The focus of this work however, has mainly been on improving student wellbeing and associated outcomes. Yet the staff are equally important to creating wellbeing in a school environment. Indeed, Rowe (2003) proposes that teachers are the most valuable resource available to a school. Barber and Mourshed (2007) argue that, "the quality of a school system rests on the quality of its teachers" (p. 14). A significant body of research indicates that other than the student themselves, teachers are the most important influence on student learning (Hattie 2003; Rowe 2003). Beyond the value of teaching staff, others at the school in non-teaching roles can also be beneficial role models for students and help to create and support a positive school environment (Kern et al. 2014b).

Answering recent calls for greater integration between positive organizational behavior and positive organizational scholarship (Youssef and Luthans 2011) the current study examines the influence of employee PsyCap and perception of OV on work happiness. First, we provide the first empirical test of Fisher's work happiness model. Second, we explore the independent and combined influence of top-down and bottom-up influences on work happiness over a 15 month period. In an applied context, this research will help practitioners further understand the impact of developing employee wellbeing through a focus on higher level constructs, and considers whether bottom-up individual-level, topdown organization level, or combined top-down, bottom-up approaches have the greatest impact on employee work happiness. We test the following hypotheses:

1. Employee PsyCap will be positively correlated with perception of virtue in the organization, such that higher levels of PsyCap contribute to seeing more virtue in the organization, and greater virtue in the organization contributes to individual-level PsyCap.

2. Employee PsyCap and perception of virtue in the organization will be independently correlated with greater employee work happiness, both cross-sectionally and prospectively.

3. PsyCap and perception of virtue in the organization will have a synergistic effect, such that together they relate to greater employee work happiness, over and above either constructs alone.

\section{Methods}

Procedure

A three-wave repeated measures correlation study was used to analyze the pattern of relationships between employee PsyCap, OV and work happiness. Employees from a large independent school in Victoria, Australia were recruited for the study through a letter and/or email from the researcher, inviting their voluntary participation to complete an online questionnaire. Individuals were included if they were employed at least 
$8 \mathrm{~h}$ per week at the school, to ensure at least a minimum level of engagement with the school. The survey was repeated at three time-points, with approximately 6 months between each one (August 2011, March 2012, November 2012). The surveys were anonymous. Before completing the survey at time 1, participants created a unique user name which they used to complete the surveys again at times 2 and 3. The participants used this unique and anonymous user-name when they completed the surveys again at time 2 and time 3 . This ensured anonymity whilst enabling the marrying of results between the three measurement occasions.

The survey was made available to all employees online via the independent survey hosting website Survey Monkey (http://www.surveymonkey.com.au). A link to the survey with information about the research was sent to all employees via the organization's email system. In order to ensure accessibility to the survey for staff groups without computer access, a paper version of the survey was also available by request from the researcher. Paper-based responses were entered into Survey Monkey manually by the researcher; this comprised a total of 11 surveys across the three measurement timepoints. Regular reminders, via email and verbal announcements at daily staff meetings, were made by the researcher throughout that time to encourage participation. The overall response rate was $75 \%$ at time $1,50 \%$ at time 2 , and $61 \%$ at time 3 .

\section{Participants}

Four hundred, thirty-two employees completed the surveys at one or more time points. Of these, 239 were members of teaching staff ( $60 \%$ female, $40 \%$ male) and 175 were employed in non-teaching roles (64\% female, $36 \%$ male). The demographic data for samples at time-points 1, 2 and 3 are shown in Table 1.

Table 1 Demographic data for the samples at each time-point

\begin{tabular}{|c|c|c|c|c|c|c|}
\hline \multirow[t]{2}{*}{ Sample } & \multirow[t]{2}{*}{ Age } & & \multicolumn{2}{|l|}{ Gender } & \multicolumn{2}{|l|}{ Role } \\
\hline & & & Female (\%) & Male (\%) & Teaching (\%) & Non-teaching (\%) \\
\hline \multirow[t]{6}{*}{ Time $1(n=247)$} & $18-25$ years & $2.43 \%$ & 60 & 40 & 40 & 60 \\
\hline & $25-34$ years & $18.62 \%$ & & & & \\
\hline & $35-44$ years & $23.89 \%$ & & & & \\
\hline & $45-54$ years & $30.77 \%$ & & & & \\
\hline & $55-64$ years & $23.08 \%$ & & & & \\
\hline & 65 years + & $0.81 \%$ & & & & \\
\hline \multirow[t]{6}{*}{ Time $2(n=165)$} & $18-25$ years & $3.64 \%$ & 65 & 35 & 62 & 38 \\
\hline & $25-34$ years & $17.58 \%$ & & & & \\
\hline & $35-44$ years & $23.03 \%$ & & & & \\
\hline & $45-54$ years & $35.15 \%$ & & & & \\
\hline & $55-64$ years & $19.39 \%$ & & & & \\
\hline & 65 years + & $1.21 \%$ & & & & \\
\hline \multirow[t]{6}{*}{ Time $3(n=199)$} & $18-25$ years & $3.02 \%$ & 56 & 44 & 61 & 39 \\
\hline & $25-34$ years & $17.09 \%$ & & & & \\
\hline & $35-44$ years & $26.3 \%$ & & & & \\
\hline & $45-54$ years & $27.64 \%$ & & & & \\
\hline & $55-64$ years & $22.61 \%$ & & & & \\
\hline & 65 years + & $3.02 \%$ & & & & \\
\hline
\end{tabular}


Sample bias analysis was conducted for the three time-point samples for levels of Psy$\mathrm{Cap}, \mathrm{OV}$, and work happiness. Comparisons were made between those responding at time 1 only, at time 1 and 2, at time 1 and 3, and at all three time points using a one-way analysis of variance (ANOVA). There were no significant differences amongst these samples, suggesting that those employees who stayed in the study through time 2 and time 3 were not significantly different in levels of PsyCap, OV, or work happiness measures compared to those employees who did not contribute to the study past time 1 . For the categorical demographic variables of gender, age and role type (teaching or non-teaching), the relationship between time group and the demographic variable were examined using Pearson's Chi square test. Large $\mathrm{p}$ values across all the tests provided no evidence of response bias (gender: $p=0.45$, role type: $p=0.38$, age: $p=0.73$ ).

\section{Materials}

The survey was developed by selecting pre-established scales to measure individual-levels of PsyCap (Luthans et al. 2007), perception of virtue in the organization (organizational virtuousness, OV, Cameron et al. 2004) and work happiness (Fisher 2010).

PsyCap PsyCap was measured through the 24-item self-rated PsyCap Questionnaire (PCQ), (Luthans et al. 2007), which has been tested in samples from service, manufacturing, high-tech, military and education sectors and across cultural settings. The four factors (self-efficacy, optimism, hope and resilience) are measured by six items adapted from pre-existing scales (hope: Snyder et al. 1996; optimism: Scheier and Carver 1985; resilience: Wagnild 1993, and efficacy: Parker 1998) with the resulting score providing an individual's level of PsyCap. Example items included: "There are lots of ways around any problem"; "When things are uncertain for me at work, I usually expect the best"; "I usually take stressful things at work in stride"; and "I feel confident presenting information to a group of colleagues". Items were scored on a 6-point Likert scale from "strongly disagree" (1) to "strongly agree" (6), and were averaged together to represent the individual's level of PsyCap (24 items, Cronbach's $\alpha_{\mathrm{t} 1}=0.94, \alpha_{\mathrm{t} 2}=0.94, \alpha_{\mathrm{t} 3}=0.92$ ).

Organizational virtuousness (OV) OV was measured using 15-item Organizational Virtuousness Scale (Cameron et al. 2004), which comprises five factors: organizational (1) forgiveness, (2) trust, (3) integrity, (4) optimism, and (5) compassion. Example items include, "we are optimistic that we will succeed, even when faced with major challenges"; "people trust the leadership of this organization"; "this organization is characterized by many acts of caring and concern for other people"; "we try to learn from our mistakes here, consequently missteps are quickly forgiven"; and "this organization demonstrates the highest levels of integrity". Items were scored on a 6-point Likert measurement scale from "strongly disagree" (1) to "strongly agree" (6) and higher scores indicate a greater perceived presence of that dimension of OV. Reliability for the overall scale was high across the three time points (15 items, $\alpha_{\mathrm{t} 1}=0.97, \alpha_{\mathrm{t} 2}=0.97, \alpha_{\mathrm{t} 3}=0.97$ ).

Work happiness Work happiness, according to Fisher (2010), is comprised of: (1) engagement with the work itself; (2) satisfaction with the job, including contextual features such as pay, co-workers, supervision and environment, and (3) feelings of affective commitment to the organization as a whole. A composite measure of work happiness does not exist, thus existing validated measures were selected for the three elements. 
Satisfaction The Job in General Scale (JIG) (Russell et al. 2004) is a measure of overall satisfaction with a job. It asks respondents to "Think of your job in general. All in all what is it like most of the time?" and lists phrases and adjectives to which respondents to select "yes, like this', if the phrase or adjective describes their current job situation, "no, not like this" if it does not or "unsure" if they cannot decide. Example items include, "good", "better than most" and "poor". Responses were scaled such that $0=$ no, $0.5=$ unsure, and $1=$ yes $\left(8\right.$ items, $\left.\alpha_{\mathrm{t} 1}=0.82, \alpha_{\mathrm{t} 2}=84, \alpha_{\mathrm{t} 3}=83\right)$.

Engagement The Utrecht Work Engagement Scale-9 (UWES-9) was used to measure work engagement. The UWES is available in 9, 15, and 17-item versions and has been tested across cultural and work settings. The 9-item version was selected in order to reduce total battery size and minimize respondent burnout and drop out, and has shown acceptable levels of reliability in past research (Schaufeli and Bakkar 2003). Example items include, "At my job I feel strong and vigorous"; "I am proud of the work that I do" and "I am immersed in my work". It is measured on a 7-point Likert scale ranging from 'Never' to 'Always/Every day' with higher scores representing higher levels of engagement $\left(\alpha_{\mathrm{t} 1}=0.92 ; \alpha_{\mathrm{t} 2}=93, \alpha_{\mathrm{t} 3}=93\right)$.

Commitment A 9-item version of the 15-item Organizational Commitment Scale (Mowday et al. 1979) was used in order to manage total battery size. The 9-item version of the scale has been used by a number of authors (Naumann and Bennett 2000; Waters 2004; Joslin et al. 2010). Example items include, "I am proud to tell others that I am part of this organization" and "I really care about the fate of this organization". The scale is scored on a 7-point Likert scale from "strongly disagree" to "strongly agree", and higher scores indicate a greater presence of commitment $\left(\alpha_{\mathrm{t} 1}=0.92, \alpha_{\mathrm{t} 2}=0.93, \alpha_{\mathrm{t} 3}=0.93\right)$.

\section{Data Analysis}

Analyzes first tested Fisher's (2010) model of workplace happiness, using confirmatory factor analysis (CFA). A higher order factor model was tested, in which work happiness was comprised of three latent factors (job satisfaction, work engagement, and organizational commitment), which in turn included the observed items (job satisfaction: 8 items, engagement: 9 items, commitment: 9 items).

To address the main hypotheses, descriptive statistics and correlations between study variables were computed. Two path models were estimated, in which work happiness at times 2 and 3 were regressed on time 1 PsyCap, OV, and work happiness (WH). Model 1 tested a serial model in which time 1 PsyCap, OV, and WH predict time $2 \mathrm{WH}$, which in turn predicts time $3 \mathrm{WH}$. Model 2 adds direct effects from time 1 PsyCap, OV, and WH predicting time $3 \mathrm{WH}$ (see Fig. 2).

Finally, to examine whether there was a synergistic effect between PsyCap and OV, five groups were created based on tertile splits on PsyCap and OV: PC + OV high (above 67\% in both constructs); PC high (above 67\% in PsyCap); OV high (above 67\% in perception of OV); PC + OV low (below 33\% in both constructs); other (all other combinations). A one-way ANOVA compared the mean scores of work happiness at each time point across these five groups.

In cases where the distributions and patterns in the residuals from the regression models indicated that the assumptions underlying the model were not met, bootstrapping was used. The bootstrap regression results, with bias corrected accelerated confidence 


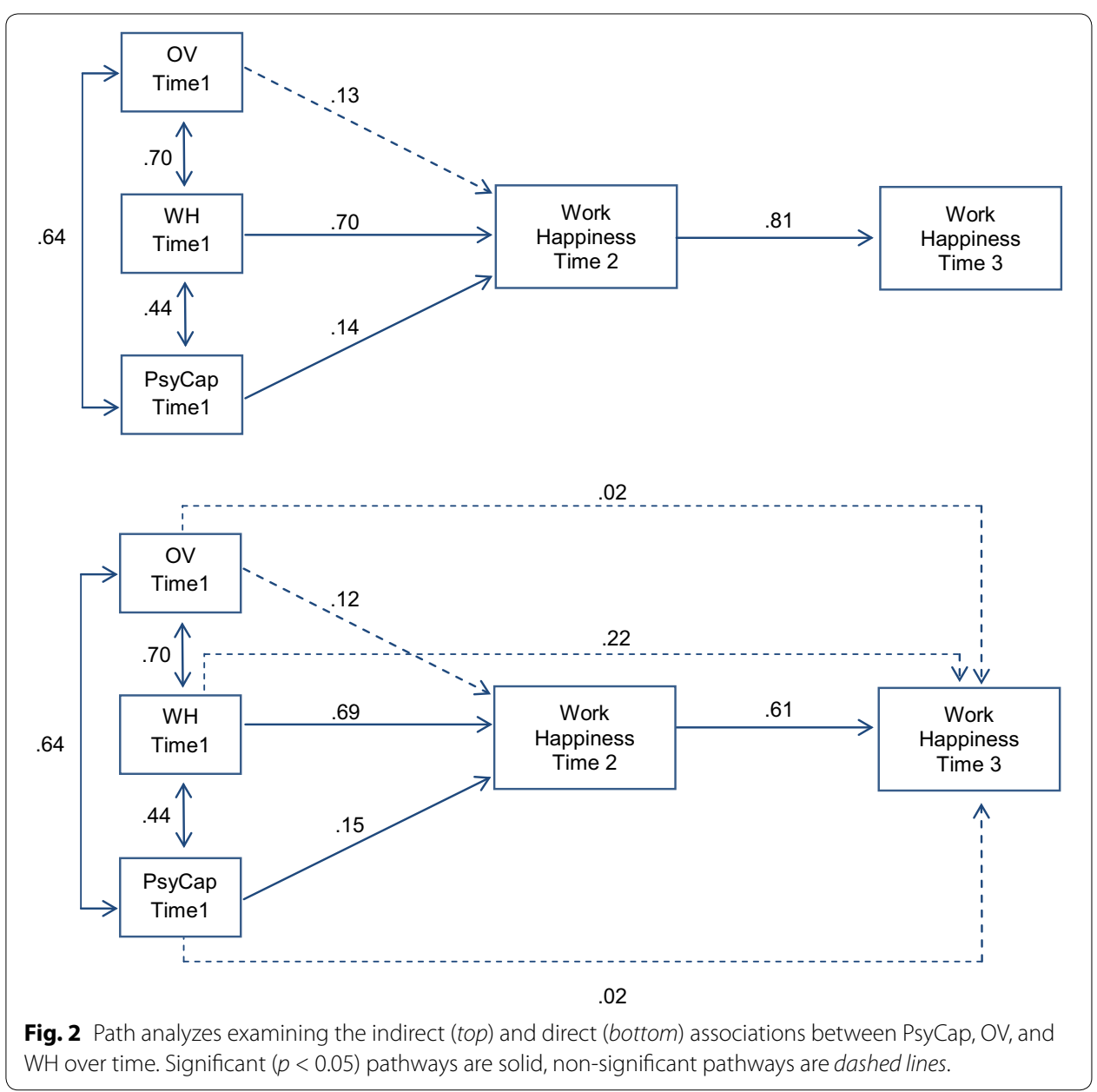

intervals, are reported. The number of cases available for analysis varied across timepoints; complete available cases were used for analysis. Descriptive, correlation, and ANOVA analyzes were conducted using SPSS (version 22.0) software; CFA and path analysis were conducted using the lavaan package (version 0.5-18; Rosseel 2012) in $R$ (version 3.1.1). Model fit was evaluated using the root mean square error of approximation (RMSEA), the standardized root mean square residual (SRMR), the comparative fit index (CFI), and the Tucker Lewis Index (TLI). For RMSEA and SRMR, values below 0.08 are considered good fit; for CFI and TLI, values above 0.90 are good fit (Hu et al. 1999).

\section{Results}

\section{Testing of Fisher's (2010) Model of Work Happiness}

Analyzes first tested Fisher's (2010) model of work happiness. Table 2 shows the items with standardized latent factor loadings and fit indices for the three time-points.

Across all three time points the model marginally fit the data. This provides some initial support for Fisher's model, but also suggests that refinements are needed to adequately measure the higher order construct. A closer look at the factor loadings indicate that questionable items were "better than most" and "excellent" for satisfaction, "I get 
Table 2 Factors and items for Fisher's theoretical model of work happiness with standardized latent factor loadings

\begin{tabular}{|c|c|c|c|}
\hline \multirow[t]{2}{*}{ Scale and items } & \multicolumn{3}{|l|}{ Loading } \\
\hline & Time1 & Time2 & Time3 \\
\hline Satisfaction & $\alpha=0.82$ & $\alpha=0.84$ & $\alpha=0.83$ \\
\hline \multicolumn{4}{|l|}{ Think of your job in general: what is it like most of the time? } \\
\hline Good & 0.66 & 0.81 & 0.73 \\
\hline Undesirable & -0.75 & -0.72 & -0.77 \\
\hline Better than most & 0.57 & 0.44 & 0.47 \\
\hline Disagreeable & -0.71 & -0.62 & -0.59 \\
\hline Makes me content & 0.73 & 0.75 & 0.66 \\
\hline Excellent & 0.57 & 0.54 & 0.53 \\
\hline Enjoyable & 0.71 & 0.86 & 0.66 \\
\hline Poor & -0.73 & -0.73 & -0.77 \\
\hline Engagement & $\alpha=0.92$ & $\alpha=0.93$ & $\alpha=0.93$ \\
\hline At my work I feel bursting with energy & 0.79 & 0.73 & 0.70 \\
\hline At my job I feel strong and vigorous & 0.85 & 0.81 & 0.78 \\
\hline I am enthusiastic about my job & 0.88 & 0.92 & 0.93 \\
\hline My job inspires me & 0.86 & 0.92 & 0.87 \\
\hline When I get up in the morning I feel like going to work & 0.79 & 0.87 & 0.80 \\
\hline I feel happy when I am working intensely & 0.73 & 0.74 & 0.65 \\
\hline I am proud of the work that I do & 0.70 & 0.80 & 0.81 \\
\hline I am immersed in my work & 0.73 & 0.72 & 0.82 \\
\hline I get carried away when I am working & 0.54 & 0.49 & 0.56 \\
\hline Commitment & $\alpha=0.92$ & $\alpha=0.93$ & $\alpha=0.93$ \\
\hline $\begin{array}{l}\text { I am willing to put in a great deal of effort beyond that normally } \\
\text { expected in order to help this organization be successful. }\end{array}$ & 0.63 & 0.72 & 0.72 \\
\hline $\begin{array}{l}\text { I talk up this organization to my friends as a great organization to } \\
\text { work for. }\end{array}$ & 0.82 & 0.89 & 0.89 \\
\hline $\begin{array}{l}\text { I would accept almost any type of job assignment in order to } \\
\text { keep working for this organization. }\end{array}$ & 0.54 & 0.54 & 0.49 \\
\hline I find that my values and the organization's values are very similar. & r. 0.77 & 0.80 & 0.83 \\
\hline I am proud to tell others that I am part of this organization & 0.87 & 0.88 & 0.89 \\
\hline $\begin{array}{l}\text { This organization really inspires the very best in me in the way of } \\
\text { job performance }\end{array}$ & 0.88 & 0.83 & 0.87 \\
\hline $\begin{array}{l}\text { I am extremely glad that I chose this organization to work for over } \\
\text { others I was considering at the time I joined. }\end{array}$ & er0.80 & 0.88 & 0.88 \\
\hline I really care about the fate of this organization. & 0.77 & 0.85 & 0.76 \\
\hline $\begin{array}{l}\text { For me this is the best of all possible organizations for which to } \\
\text { work. }\end{array}$ & 0.79 & 0.85 & 0.81 \\
\hline \multicolumn{4}{|l|}{ Higher order factor } \\
\hline Satisfaction & 0.84 & 0.85 & 0.84 \\
\hline Engagement & 0.85 & 0.85 & 0.89 \\
\hline Commitment & 0.76 & 0.79 & 0.70 \\
\hline \multicolumn{4}{|l|}{ Fit Indices } \\
\hline $\mathrm{N}$ & 260 & 178 & 207 \\
\hline RMSEA (90\% confidence interval) & $0.10(0.09,0.10)$ & $0.12(0.11,0.13)$ & $0.11(0.11,0.12)$ \\
\hline Standardized Root Mean Square Residual (SRMR) & 0.064 & 0.09 & 0.07 \\
\hline Comparative Fit Index (CFI) & 0.85 & 0.81 & 0.82 \\
\hline Tucker Lewis Index (TLI) & 0.84 & 0.79 & 0.80 \\
\hline
\end{tabular}

Latent model estimated in $\mathrm{R}$ using the lavaan package (Rosseel 2012). 
carried away when I am working" for engagement, and "I would accept almost any type of job assignment in order to keep working for this organization" for commitment. However, removing these items did not improve model fit. As developing a measure of work happiness is beyond the scope of the current study, we proceeded with these items as our measure of work happiness, but the measurement error inherent to the measure should be kept in mind in interpreting the results. Items were combined into the three first order factors, and then the three first order factors were standardized and averaged to create single work happiness variables $\left(\alpha_{\mathrm{t} 1}=0.92, \alpha_{\mathrm{t} 2}=94, \alpha_{\mathrm{t} 3}=94\right)$.

\section{Associations Among PsyCap, OV, and Work Happiness}

Table 3 shows the means, standard deviations and correlations amongst PsyCap, OV, and work happiness within and across the three measurement time-points. As predicted, PsyCap and OV were strongly positively correlated with one another, both crosssectionally and over time, such that individuals with greater PsyCap perceived greater $\mathrm{OV}$ in the organization, and vice versa. Both PsyCap and OV also strongly correlated with work happiness, with a simplex structure (i.e., variables closer in time are more strongly correlated, with correlation strength declining over time). For example, the correlation between Time 1 PsyCap and work happiness was $r=0.65$, whereas the correlation between Time 1 PsyCap and Time 3 work happiness was $r=0.45$.

Figure 2 summarizes two path models testing prospective associations between Time 1 PsyCap and OV and subsequent work happiness, controlling for Time 1 work happiness. Not surprisingly, work happiness was by far the strongest predictor of subsequent work happiness. PsyCap and OV directly related to greater workplace happiness at Time 2 , but were only indirectly related to workplace happiness at Time 3.

\section{Synergistic Effect}

Finally, the synergistic effect of PsyCap and OV on work happiness was tested. Figure 3 shows the mean scores and 95\% confidence intervals for the five groups at each time point.

The mean comparison suggests that there is a small synergistic effect between PsyCap and $\mathrm{OV}$, but that having high levels of both or one of the constructs influences levels

Table 3 Means, standard deviations and correlations for PsyCap, organizational virtuousness (OV) and work happiness within and across three measurement time-points

\begin{tabular}{|c|c|c|c|c|c|c|c|c|c|c|c|c|}
\hline Variable & $\mathbf{N}$ & M & SD & 1 & 2 & 3 & 4 & 5 & 6 & 7 & 8 & 9 \\
\hline 1. PsyCap Time 1 & 260 & 4.75 & 0.63 & 1.00 & & & & & & & & \\
\hline 2. OVTime 1 & 249 & 4.77 & 0.90 & 0.45 & 1.00 & & & & & & & \\
\hline 3. Work happiness Time 1 & 260 & 4.38 & 0.86 & 0.65 & 0.70 & 1.00 & & & & & & \\
\hline 4. PsyCap Time 2 & 182 & 4.77 & 0.62 & 0.86 & 0.51 & 0.58 & 1.00 & & & & & \\
\hline 5. OVTime 2 & 171 & 4.91 & 0.84 & 0.54 & 0.79 & 0.73 & 0.47 & 1.00 & & & & \\
\hline 6. Work happiness Time 2 & 178 & 4.73 & 0.87 & 0.66 & 0.61 & 0.85 & 0.64 & 0.73 & 1.00 & & & \\
\hline 7. PsyCap Time 3 & 206 & 4.81 & 0.55 & 0.71 & 0.31 & 0.48 & 0.73 & 0.41 & 0.47 & 1.00 & & \\
\hline 8. OVTime 3 & 198 & 4.88 & 0.81 & 0.29 & 0.71 & 0.45 & 0.36 & 0.78 & 0.55 & 0.51 & 1.00 & \\
\hline 9. Work happiness Time 3 & 207 & 4.50 & 0.86 & 0.45 & 0.42 & 0.63 & 0.41 & 0.50 & 0.72 & 0.59 & 0.65 & 1.00 \\
\hline
\end{tabular}

Work happiness is the average standardized scores on job satisfaction, engagement, and commitment, with a constant added to eliminate negative values. All $p s<0.01$. 


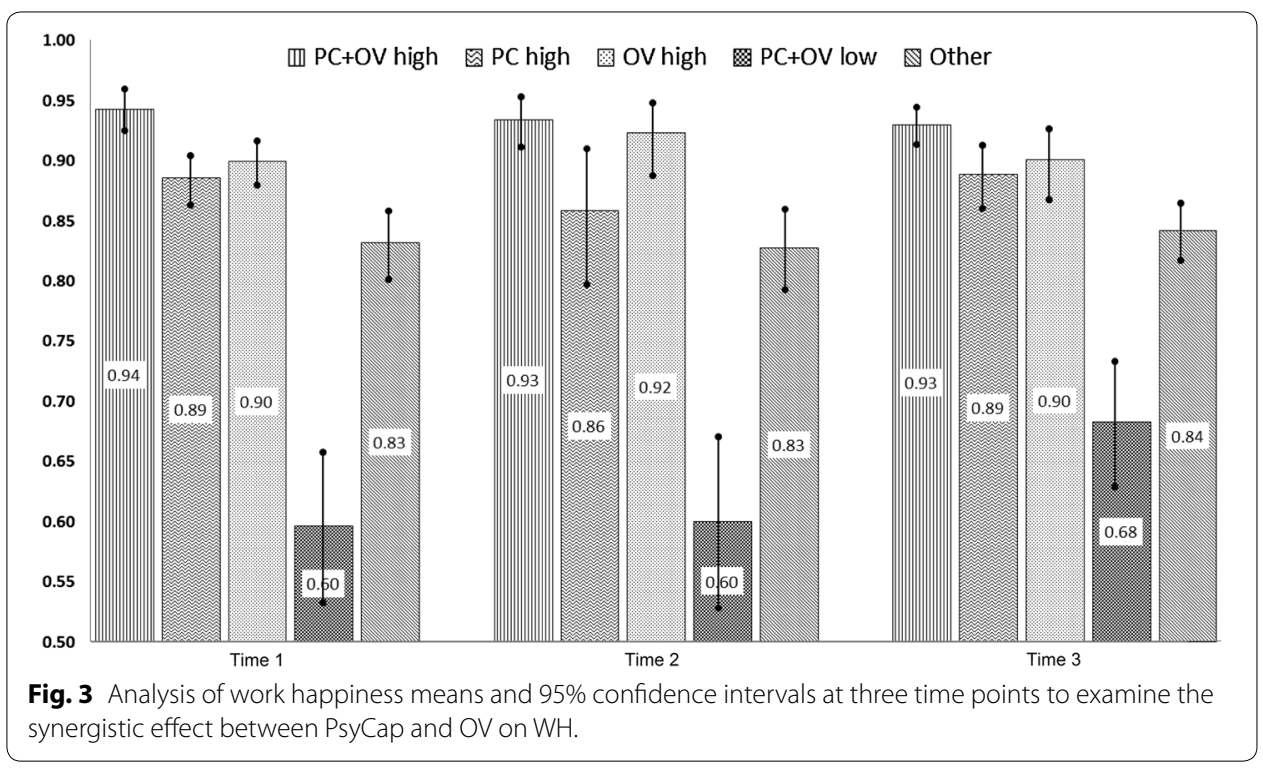

of work happiness when compared to having low levels of both. The lack of synergy between PsyCap and OV may be explained by a ceiling effect in the measures used in this study, as the mean scores of the 'high' groups (67\% and above tertile) were close to the maximum scores of the measures.

\section{Discussion}

Bringing together the top-down perspective of positive organizational scholarship with the bottom-up approaches of positive organizational behavior, this study examined the combined effect of employee PsyCap and perception of virtue in the organization (OV) on work happiness. The examinations were performed cross-sectionally and prospectively across a 15 month period. Taken together, the regression analysis, path analysis models, and work happiness mean score comparisons suggest that work happiness can be predicted directly and separately by PsyCap and OV (within and across time). Further, a synergistic effect between the constructs may exist, although this effect is seemingly limited by a ceiling effect with the measures used in this study.

Within and across time, PsyCap and OV were positively associated with one another. It may be that increased PsyCap enables employees to see virtues in their work environment more explicitly. For example, an optimistic employee believes that good things will happen to them (Carver and Scheier 2002). This may influence their motivational state and lead to evaluative processes that allow them to more clearly see the presence of the virtue of optimism in their organization. For example, if a leader introduces a new virtues-based practice at work, employees with high optimism may have a positive predisposition to see the virtue in that new initiative. The underlying explanation for this rests on the idea of attitudes. Attitudes have been found to help categorize objects (Smith et al. 1996), assist decision-making ease (Blascovich et al. 1993) and decisionmaking quality (Fazio et al. 1992). Thus employees with optimistic attitudes could be more likely to evaluate virtuous practices and policies within the organization through a lens of optimism. 
Both PsyCap and OV were also correlated with greater reported work happiness, cross-sectionally and over time. Employees with high PsyCap are hopeful and have positive expectations about future outcomes and they have greater confidence in their ability to deal with challenges and higher levels of resilience. This may provide them with the resources to perform well in their job, thus enabling and supporting their work happiness.

Past research has considered individual-level aspects of organizational climate (e.g., gratitude or trust or compassion) and how these influence worker wellbeing/happiness. Waters (2012) found a significant association between gratitude as a cultural variable at work and levels of job satisfaction in employees. Further, there is evidence that experiencing compassion at work increases member experience of positive emotions (Lilius et al. 2012). Finally, organizational trust has been shown to have a positive relationship with employee satisfaction (Dirks and Ferrin 2001; Rich 1997) and their levels of organizational commitment (Brockner et al. 1997; Dirks and Ferrin 2001).

Past research as also shown that workplace culture influences employee levels of emotional wellbeing (Hartel and Ashkanasy 2011). The current study found that perception of a virtuous culture was related to the work happiness of employees. Organizational virtuousness can be considered as a virtues-based culture that manifests through observable artefacts, espoused values, shared beliefs and collective behaviors. For example, virtues-based practices such as gratitude boards (to support compassion and optimism) or leaders beginning meetings with 'what went well' exercise (to support optimism and trust) provide observable artifacts of the virtuous culture and opportunities to foster virtues through espoused values. Moving deeper than the use of practices, other elements of culture, such as shared beliefs and collective behaviors may be influenced by embedding virtues in organizational behaviors, leadership (Cameron et al. 2011), engaging in strengths-based performance conversations (Bouskila-Yam and Kluger 2011) and infusing virtues into training, development and coaching. Together, these virtue-infused elements of culture may provide organizational resources that influence the quality of relationship between the organization and employee such that their happiness at work increases. For example, a workplace culture in which leaders are optimistic about the future, compassionate in their communication and forgiving when needed, may help develop supportive leader-worker relations and a supportive work community; relationships and community are social resources that may help to develop employee happiness at work (Fisher 2010).

Haidt's (2000) elevation hypothesis can also be used to explain the study results. Employees who perceive more virtuousness in the behavior of colleagues and see more virtue in organizational practices, may be motivated to behave more virtuously themselves. This virtuous behavior can lead to positive core self-evaluation and resilience. Given the link between virtuous behavior and wellbeing that has been established in past research (Proudfoot et al. 2009) this may explain why the current sample of employees reported a relationship between their perception of OV and happiness at work.

When turning to the longitudinal data, the associations between PsyCap, OV, and work happiness were not as strong over time as those within the same time-points. These results provide a temporal understanding of the associations between the variables, which has practical implications for organizations. 
Both independently and together, PsyCap and OV had a stronger association with work happiness over time than either variable alone. This suggests that top-down influences on employee work happiness (e.g. the use of positive practices, Cameron et al. 2011) and bottom-up influences on work happiness (such as developing employee PsyCap) have independent and synergistic associations. Therefore, organizations need to focus efforts on developing both individual-level resources (PsyCap) and organizationallevel resources (virtues present in the organization, OV) to support employee wellbeing.

The current research has a number of limitations. The correlational design of the study limits our ability to draw conclusions about causality of the associations between PsyCap, OV, and work happiness. For example, within-time results showed significant associations between the three variables, however because of the correlational study design, we cannot draw conclusions about whether higher PsyCap causes employees to have higher levels of work happiness; whether higher levels of work happiness causes people to have higher PsyCap or whether there is a third unidentified variable that underlies the associations. It may be, for example, that employee attitudes are an underlying mechanism that if tested would provide a better understanding of how employee PsyCap and OV influence work happiness over time. Future research should investigate attitudes as a possible underlying mechanism in order to more fully understand the complexity of these relationships. Measures were also self-reported, and method variance could influence correlations. The use of objective measures of organizational virtues or workplace happiness will be valuable in the future.

The main outcome variable, work happiness, is built upon Fisher's (2010) model. To date, there is not a single measure that assesses the three inter-related domains proposed by the model. The current study therefore combined three psychometrically validated measures to approximate such a measure. Although the items provided some support for Fisher's model, model fit could be considerably improved, to the extent that the very strong correlations amongst study variables could reflect inadequate measurement of the underlying constructs. Further testing of Fisher's model, with a related valid measure, is needed.

The study was conducted with employees who work in a school following the growing interest in positive education to study staff wellbeing in addition to the current major focus of positive education on student wellbeing (Kern et al. 2014a; Kristjánsson 2012; Waters and Stokes 2015). While the use of this sample adds to the file of positive education it may not be generalizable to workers from other sectors.

Despite these limitations, the study has a number of strengths. The study provides a first empirical test of Fisher's (2010) theory of employee work happiness. It includes both top-down organization aspects and bottom-up employee aspects thus responding to Sloan's (1987) idea of dual-intervention. The longitudinal nature of the study provides a valuable temporal understanding to the patterns of the associations between PsyCap, $\mathrm{OV}$, and work happiness. The quantitative analysis is appropriate to examine associations between PsyCap, OV, and work happiness to see what naturally occurs without intervention efforts (Creswell 2003). 


\section{Conclusion}

Over recent years there has been increasing evidence that links employee happiness to a broad range of positive individual-level and organizational-level outcomes (Fisher 2010). This has led organizations to value the importance of employee happiness and to want to know how it is that employee happiness can be increased (Fisher 2010). The current research adopted Sloan's (1987) dual-intervention approach and examined the interrelationships between employee happiness with a bottom-up, individual-level variable (psychological capital) and with a top-down, organizational-level variable (organizational virtue) within and between three time-points. Rather than study a multitude of individual-level variables and how they relate to individual-level aspects of happiness at work, the current study examined three higher order constructs that have recently been proposed in the fields of POS and POB. The higher order approach allows for shared variance between individual constructs and, ultimately provides a more parsimonious way for approach for studying associations amongst these constructs.

By investigating these interrelationships between work happiness, PsyCap and organizational virtues with a sample of school employees, the study integrates aspects of the fields of positive organizational scholarship, positive organizational behavior and positive education. In an applied setting, the results can be used to help schools and other organizations understand the importance of developing the personal resources of employees (PsyCap) and the culture of the organization to enhance employee work happiness. We hope this study inspires further research into the factors that influence employee happiness at work.

Authors' contributions

PW led the research, conducted the primary analyses, and drafted and revised the manuscript. MK supervised the analyses and helped revise the manuscript. LW supervised and contributed to the original data analysis and the revision of the manuscript. All authors read and approved the final manuscript.

Compliance with ethical standards

Competing interests

The authors declare that they have no competing interests.

Received: 15 December 2014 Accepted: 7 July 2015

Published online: 28 July 2015

References

Albrecht, S. L. (2010). Handbook of employee engagement: perspectives, issues, research and practice. UK: Edward Elgar Publishing.

Allen, N. J., \& Meyer, J. P. (1990). The measurement and antecedents of affective, continuance and normative commitment to the organization. Journal of Occupational Psychology, 63(1), 1-18.

Armutlulu, I. H., \& Noyan, F. (2011). A multilevel model of organizational commitment. Procedia-Social and Behavioral Sciences, 30, 2139-2143. doi:10.1016/j.sbspro.2011.10.415.

Avey, J. B., Luthans, F., Smith, R. M., \& Palmer, N. F. (2010). Impact of positive psychological capital on employee well-being over time. Journal of Occupational Health Psychology, 15(1), 17-28. doi:10.1037/a0016998.

Avey, J. B., Patera, J. L., \& West, B. J. (2006). Positive psychological capital: a new approach for understanding absenteeism. Journal of Leadership and Organisational Studies, 13, 42-60.

Bakker, A. B., \& Demerouti, E. (2008). Towards a model of work engagement. Career Development International, 13(3), 209-223. doi:10.1108/13620430810870476.

Barber, M., Mourshed, M. (2007). How the world's best performing school systems come out on top. Analysis, executive summary.

Bartlett, C. A., \& Ghoshal, S. (2002). New organizational responses. Strategy: Critical Perspectives on Business and Management, 3(1), 468.

Blascovich, J., Ernst, J. M., Tomaka, J., Kelsey, R. M., Salomon, K. L., \& Fazio, R. H. (1993). Attitude accessibility as a moderator of autonomic reactivity during decision making. Journal of Personality and Social Psychology, 64(2), 165. 
Boehm, J. K., \& Lyubomirsky, S. (2008). Does happiness promote career success? Journal of Career Assessment, 16(1), $101-116$.

Bouskila-Yam, O., \& Kluger, A. N. (2011). Strength-based performance appraisal and goal setting. Human Resource Management Review, 21(2), 137-147.

Brockner, J., Siegel, P. A., Daly, J. P., Tyler, T., Martin, C. (1997). When trust matters: the moderating effect of outcome favorability. Administrative Science Quarterly, 42, 558-583.

Cameron, K. S., Bright, D., \& Caza, A. (2004). Exploring the relationships between organizational virtuousness and performance. American Behavioral Scientist, 47(6), 766-790. doi:10.1177/0002764203260209.

Cameron, K., Dutton, J., \& Quinn, R. (2003). An introduction to positive organizational scholarship. Positive organizational scholarship. San Francisco: Berrett-Koehler.

Cameron, K., Mora, C., Leutscher, T., \& Calarco, M. (2011). Effects of positive practices on organizational effectiveness. The Journal of Applied Behavioral Science, 47(3), 266-308. doi:10.1177/0021886310395514.

Carver, C. S., \& Scheier, M. F. (2002). The hopeful optimist. Psychological Inquiry, 13(4), 288-290.

Cotton, P., \& Hart, P. M. (2003). Occupational wellbeing and performance: a review of organisational health research. Australian Psychologist, 38(2), 118-127.

Creswell, J. W. (2003). Research design : qualitative, quantitative and mixed methods approaches, 2nd ed. CA: Sage Publications.

Dirks, K. T., \& Ferrin, D. L. (2001). The role of trust in organizational settings. Organization Science, 12(4), 450-467.

Faragher, E. B., Cass, M., \& Cooper, C. L. (2005). The relationship between job satisfaction and health: a meta-analysis. Occupational and Environmental Medicine, 62(2), 105-112.

Fazio, R. H., Blascovich, J., \& Driscoll, D. M. (1992). On the functional value of attitudes: the influence of accessible attitudes on the ease and quality of decision making. Personality and Social Psychology Bulletin, 18(4), 388-401.

Fisher, C. D. (1997). Emotions at work: what do people feel and how should we measure it? School of Business Discussion Papers, 63. Retrieved from http://epublications.bond.edu.au/cgi/viewcontent.cgi?article $=1066 \&$ context=discus sion_papers\&sei-redir=1\&referer=http\%3A\%2F\%2Fscholar.google.com.au\%2Fscholar\%3Fhl\%3Den\%26q\%3DFis her\%2BCD.\%2BEmotions\%2Bat\%2Bwork\%253A\%2BWhat\%2Bdo\%2Bpeople\%2Bfeel\%2Band\%2Bhow\%2Bshould \%2Bwe\%2Bmeasure\%2Bit\%253F\%26btnG\%3D\%26as_sdt\%3D1\%252C5\%26as_sdtp\%3D\#search=\%22Fisher\%20 CD.\%20Emotions\%20work\%3A\%20What\%20do\%20people\%20feel\%20how\%20should\%20measure\%20it\%3F\%22. Accessed 7 Dec 2014.

Fisher, C. D. (2010). Happiness at work. International Journal of Management Reviews, 12(4), 384-412. doi:10.1111/j.1468-2370.2009.00270.x.

Giardini, A., \& Frese, M. (2008). Linking service employees' emotional competence to customer satisfaction: a multilevel approach. Journal of Organizational Behavior, 29(2), 155-170

Gorgievski, M. J., Bakker, A. B., \& Schaufeli, W. B. (2010). Work engagement and workaholism: comparing the selfemployed and salaried employees. The Journal of Positive Psychology, 5(1), 83-96.

Hackman, J. R., \& Oldham, G. R. (1976). Motivation through the design of work: test of a theory. Organizational Behavior And Human Performance, 16(2), 250-279.

Haidt, J. (2000). The Positive emotion of elevation. Prevention \& Treatment, 3(1). Retrieved from http://psycnet.apa.org/ journals/pre/3/1/3c/. Accessed 2 Feb 2012.

Hartel, C. E. J., \& Ashkanasy, Neal M. (2011). Healthy human cultures as positive work environments (2nd ed.). Thousand Oaks: Sage Publications.

Harter, J. K., Schmidt, F. L., \& Keyes, C. L. (2003). Well-being in the workplace and its relationship to business outcomes: a review of the Gallup studies. Flourishing: Positive Psychology and the Life Well-Lived, 2, 205-224.

Hattie, J. (2003). Building teacher quality: what does the research tell us? http://research.acer.edu.au. Retrieved from http://research.acer.edu.au/research_conference_2003/4. Accessed 14 Feb 2012.

Hobfoll, S.E., Johnson, R.J., Ennis, N., Jackson, A.P. (2003). Resource loss, resource gain, and emotional outcomes among inner city women. Journal of Personality and Social Psychology, 84(3), 632-643.

Hu, L. T., \& Bentler, P. M. (1999). Cutoff criteria for fit indexes in covariance structure analysis: conventional criteria versus new alternatives. Structural Equation Modeling: a Multidisciplinary Journal, 6(1), 1-55.

Huppert, F. A., \& So, T. T. (2013). Flourishing across Europe: application of a new conceptual framework for defining wellbeing. Social Indicators Research, 110(3), 837-861.

Joslin, F., Waters, L., \& Dudgeon, P. (2010). Perceived acceptance and work standards as predictors of work attitudes and behavior and employee psychological distress following an internal business merger. Journal of Managerial Psychology, 25(1), 22-43.

Judge, T. A., \& Kammeyer-Mueller, J. D. (2012). Job attitudes. Annual Review of Psychology, 63(1), 341-367. doi:10.1146/ annurev-psych-120710-100511.

Judge, T. A., Piccolo, R. F., \& llies, R. (2004). The forgotten ones? The validity of consideration and initiating structure in leadership research. Journal of Applied Psychology, 89(1), 36-51.

Judge, T. A., Thoresen, C. J., Bono, J. E., \& Patton, G. K. (2001). The job satisfaction-job performance relationship: a qualitative and quantitative review. Psychological Bulletin, 127(3), 376.

Kern, M.L., Waters, L.E., Adler, A., White, M. (2014a). A multidimensional approach to measuring well-being in students: application of the PERMA framework. The Journal of Positive Psychology, 10(3), 262-271. doi:10.1080/17439760.2014 .936962.

Kern, M. L., Waters, L., Adler, A., \& White, M. (2014b). Assessing employee wellbeing in schools using a multifaceted approach: associations with physical health, life satisfaction, and professional thriving. Psychology, 5(06), 500.

Keyes, C. L. (2005). Mental illness and/or mental health? Investigating axioms of the complete state model of health. Journal of Consulting and Clinical Psychology, 73(3), 539.

Kristjánsson, K. (2012). Positive psychology and positive education: old wine in new bottles? Educational Psychologist, $47(2), 86-105$.

LePine, J. A., Erez, A., \& Johnson, D. E. (2002). The nature and dimensionality of organizational citizenship behavior: a critical review and meta-analysis. Journal of Applied Psychology, 87(1), 52-65. doi:10.1037//0021-9010.87.1.52. 
Lilius, J. M., Kanov, J. M., Dutton, J. E., Worline, M. C., \& Maitlis, S. (2012). Compassion revealed: what we know about compassion at work (and where we still need to know more). In K. S. Cameron \& G. Spreitzer (Eds.), The handbook of positive organizational scholarship (pp. 273-287). New York: Oxford University.

Locke, E. A. (1976). The nature and causes of job satisfaction. In M. D. Dunnette (Ed.), Handbook of industrial and organizational psychology (pp. 1297-1347). Chicago: Rand McNally.

Lorange, P. (2005). Strategy means choice: also for today's business school! Journal of Management Development, 24(9), 783-790. doi:10.1108/02621710510621295.

Luthans, F., Avolio, B.J., Avey, J.B. (2007). Psychological capital questionnaire. Mind Garden. Retrieved from http://www. mindgarden.com. Accessed 14 Feb 2012.

Luthans, F., Avolio, B. J., Avey, J. B., \& Norman, S. M. (2007b). Positive psychological captial : measurement and relationship with performance and satisfaction. Personnel Psychology, 60, 541-572.

Luthans, F., Avolio, B. J., Walumbwa, F. O., \& Li, W. (2005). The psychological capital of Chinese workers: exploring the relationship with performance. Management and Organization Review, 1(2), 249-271.

Luthans, K. W., \& Jensen, S. M. (2005). The linkage between psychological capital and commitment to organisational mission : a study of nurses. Journal of Nursing Administration, 35(6), 304-310.

Luthans, F., Youssef, C. M., \& Avolio, B. J. (2006). Psychological capital: Developing the human competitive edge. USA: Oxford University Press.

Meyer, J. P., \& Allen, N. J. (1984). Testing the" side-bet theory" of organizational commitment: some methodological considerations. Journal of Applied Psychology, 69(3), 372.

Meyer, J. P., Stanley, D. J., Herscovitch, L., Topolnytsky, L. (2002). Affective, continuance, and normative commitment to the organization: a meta-analysis of antecedents, correlates, and consequences. Journal of Vocational Behavior, 61(1), 20-52. doi:10.1006/jvbe.2001.1842

Morrow, P. C. (2011). Managing organizational commitment: insights from longitudinal research. Journal of Vocational Behavior, 79(1), 18-35. doi:10.1016/j.jvb.2010.12.008.

Mowday, R. T., Steers, R. M., \& Porter, L. W. (1979). The measurement of orgnisational commitment. Journal of Vocational Behavior, 14, 224-247.

Naumann, S. E., \& Bennett, N. (2000). A case for procedural justice climate: development and test of a multilevel model. Academy of Management Journal, 43(5), 881-889.

Norrish, J. M., Williams, P., O'Connor, M., Robinson, J. (2013). An applied framework for positive education. International Journal of Wellbeing, 3(2), 147-161.

Page, K. (2005). Subjective wellbeing in the workplace. PhD Thesis, Deakin University.

Page, K., \& Vella-Brodrick, D. (2009). The 'What','Why' and 'How' of employee well-being: a new model. Social Indicators Research, 90(3), 441-458. doi:10.1007/s11205-008-9270-3.

Park, N., \& Peterson, C. (2003). Virtues and organizations. In J. E. D. K. S. Cameron \& R. E. Quinn (Eds.), Positive organizational scholarship: foundations of a new discipline (pp. 33-47). San Francisco: Berrett-Koehler.

Parker, S. (1998). Enhancing role breadth self-efficacy : the roles of job enrichment and other organisational interventions. Journal of Applied Psychology, 83, 835-852.

Peterson, C., Seligman, M. E. P. (2004). Character strengths and virtues : a handbook and classification. Washington D.C.: American Psychological Association.

Price Waterhouse Coopers. (2014). Workplace Wellness in Australia.

Proudfoot, J. G., Corr, P. J., Guest, D. E., \& Dunn, G. (2009). Cognitive-behavioral training to change attributional style improves employee well-being, job satisfaction, productivity, and turnover. Personality and Individual Differences, 46(2), 147-153.

Rich, G. A. (1997). The sales manager as a role model: Effects on trust, job satisfaction, and performance of salespeople. Journal of the Academy of Marketing Science, 25(4), 319-328.

Rosseel, Y. (2012). lavaan: An R package for structural equation modeling. Journal of Statistical Software, 48(2), 1-36.

Rowe, K (2003). The importance of teacher quality as a key determinant of students' experiences and outcomes of schooling. In Dennis M. McInerney SVE, Martin Dowson (Ed.), Standards in education (pp. 59-92). USA: Information Age Publishing. http://research.acer.edu.au. Retrieved from http://research.acer.edu.au/research_conference_2003/3. Accessed 2 Feb 2012.

Russell, S. S., Spitzmüller, C., Lin, L. F., Stanton, J. M., Smith, P. C., \& Ironson, G. H. (2004). Shorter can also be better: the abridged job in general scale. Educational and Psychological Measurement, 64(5), 878-893.

Schaufeli, W., \& Bakkar, A. (2003). Utrecht work angegement scale preliminary manual. Utrecht: Occupational Health Psychology Unit, Utrecht University.

Scheier, M., \& Carver, C. (1985). Optimism, coping, and health: assessment and implications of generalized outcome expectancies. Health Psychology, 4, 219-247.

Seligman, M. E. (2011). Flourish: a visionary new understanding of happiness and well-being. New York: Free Press.

Seligman, M. E., Ernst, R. M., Gillham, J., Reivich, K., \& Linkins, M. (2009). Positive education: positive psychology and classroom interventions. Oxford Review of Education, 35(3), 293-311.

Sloan, R. P. (1987). Workplace health promotion: a commentary on the evolution of a paradigm. Health Education and Behavior, 14(2), 181-194.

Smith, E. R., Fazio, R. H., \& Cejka, M. A. (1996). Accessible attitudes influence categorization of multiply categorizable objects. Journal of Personality and Social Psychology, 71(5), 888.

Snyder, C. R., Sympson, S. C., Ybasco, F. C., Borders, T. F., Babyak, M.A., Higgins, R. L. (1996). Development and validation of the hope scale. Journal of Personality and Social Psychology, 70(2), 321-335. doi:10.1037/0022-3514.70.2.321 .

Spreitzer, G. M., \& Sonenshein, S. (2004). Toward the construct definition of positive deviance. American Behavioral Scientist, 47(6), 828-847. doi:10.1177/0002764203260212.

Wagnild, G. Y. H (1993). Development and psychometric evaluation of the resiliience scale. Journal of Nursing Measurement, 165-178.

Waters, L. (2004). Protege-mentor fit in perceptions of the provision of psychosocial support: the role of personality, job involvement, workload and the mentoring relationship. Journal of Vocational Behaviour, 65, 519-532. 
Waters, L. (2011). A review of school-based positive psychology interventions. The Australian Educational and Developmental Psychologist, 28(02), 75-90.

Waters, L. (2012). Predicting job satisfaction: contributions of individual gratitude and institutionalized gratitude. Psychology, 3,1174

Waters, L., Stokes, H. (2015). Positive education for school leaders: exploring the effects of emotion-gratitude and actiongratitude. The Australian Educational and Developmental Psychologist, 32(1), 1-22.

Wright, T. A., \& Bonett, D. G. (2007). Job satisfaction and psychological well-being as nonadditive predictors of workplace turnover. Journal of Management, 33(2), 141-160.

Youssef, C. M., \& Luthans, F. (2011). Positive psychological capital in the workplace: where we are and where we need to go. In Kennon M. Sheldon, T. B. Kashdan, Michael F. Steger (Eds.), Designing positive psychology: taking stock and moving forward (pp. 351-364). USA: Oxford University Press.

Submit your manuscript to a SpringerOpen ${ }^{\circ}$ journal and benefit from:

- Convenient online submission

Rigorous peer review

- Immediate publication on acceptance

- Open access: articles freely available online

- High visibility within the field

- Retaining the copyright to your article

Submit your next manuscript at $\boldsymbol{s p r i n g e r o p e n . c o m ~}$ 